As meninas: uma análise dos efeitos de sentido produzidos a partir do funcionamento discursivo do depoimento de um preso político no discurso fílmico e literário | 61

\title{
AS MENINAS: UMA ANÁLISE DOS EFEITOS DE SENTIDO PRODUZIDOS A PARTIR DO FUNCIONAMENTO DISCURSIVO DO DEPOIMENTO DE UM PRESO POLÍTICO NO DISCURSO FÍLMICO E LITERÁRIO
}

RESUMO: Este trabalho ${ }^{21}$, sustentado teoricamente na Análise do Discurso de viés pêcheuxtiano, tem por objetivo analisar os efeitos de sentido produzidos pelo depoimento "verídico" de um preso político durante a ditadura militar brasileira, que Lygia Fagundes Telles insere na obra literária As Meninas e que também é reproduzido no filme de mesmo nome. Apresento uma análise da cena narrativo-fílmica e da cena narrativo-literária, considerando essas cenas como condições de produção de discurso e a constituição dos possíveis efeitos de sentido que, do entrecruzamento entre elas, pode emergir. No intuito de alcançar tais objetivos, se toma o recorte do filme e o recorte do livro como materialidades discursivas que se constituem afetados pela história e pela ideologia.

Palavras-chave: discurso; cinema; literatura; gênero; ditadura brasileira.

ABSTRACT: This work, theoretically sustained in the Analysis of Discourse proposed by Pêcheux, aims to analyze the effects of meaning produced by the 'true' statement of a political prisoner during the Brazilian military dictatorship, which Lygia Fagundes Telles put in her work and is also reproduced in the film. I will try to present an analysis of the narrative-film scene and narrative-literary scene, considering these

20 Doutora em Letras. Professora de Língua Inglesa no Instituto Federal de Educação, Ciência e Tecnologia Sul-rio-grandense. Membro dos grupos de pesquisa Grupo de Estudos Pecheutianos (GEP-Unipampa) e Laboratório de Estudos em Análise de Discurso (LEAD-UFPel).

${ }^{21}$ A proposta deste trabalho surgiu na disciplina Discursos Entrecruzados: Literatura, Gênero e Cinema ministrada pela Profa. Dra. Eliane Campello no Programa de PósGraduação em Letras da UCPel. Procurando aliar os discursos literário e fílmico, a proposta era relacionar as obras, tendo como pano de fundo a questão de gênero, uma vez que todos os filmes analisados tiveram seus roteiros adaptados de livros escritos por mulheres. 
scenes as discourse production conditions and the establishment of the possible effects of meaning that the intersection between them can emerge. In order to achieve these objectives, cuttings of the film and the book are considered as discursive materialities that are affected by history and ideology.

Keywords: discourse; cinema; literature; gender; Brazilian dictatorship.

A proposta do presente texto é apresentar uma reflexão de como, tomando a relação entre literatura e cinema, é possível vislumbrar a produção de efeitos de sentido, tendo como pano de fundo teórico a Análise do Discurso pêcheuxtiana. $O$ recorte foi consolidado através da mobilização dos dispositivos teóricos e analíticos, refinando-se o objetivo do trabalho em analisar a produção de sentidos advindos do funcionamento do discurso direto, materializado na forma de depoimento de um torturado pelas forças opressoras da ditadura militar brasileira, encontrado nas obras literária e fílmica As Meninas.

A primeira obra é o romance escrito por Lygia Fagundes Telles publicado em 1973 no Brasil. E a segunda obra é o filme dirigido por Emiliano Ribeiro, produzido em 1995 e lançado em 1996. Considerando o entroncado caminho escolhido, propõe-se realizar a análise com base nos preceitos teóricos que vêm sendo formulados pela Análise do Discurso (AD), trazendo alguns estudos atuais que levam em consideração a relação entre a $\mathrm{AD}$ e o cinema e a $\mathrm{AD}$ e a literatura.

Consoante Orlandi

Estamos, pois, no momento de uma virada na análise de discurso. Inauguração de um novo campo de questões. Uma nova conjuntura histórica, novas formas de existência histórica das discursividades leva a análise de discurso a novas indagações (ORLANDI, 2012, p. 44).

Essa virada teórica diz respeito, dentre outros aspectos, aos diferentes objetos de análise discursiva que têm surgido nos últimos tempos e que extravasam o limite textual, num tatear sobre a imagem e o literário como discurso.

Indursky aponta que 
As meninas: uma análise dos efeitos de sentido produzidos a partir do funcionamento discursivo do depoimento de um preso político no discurso fílmico e literário | 63

Hoje, são inúmeros os trabalhos que consideram o não-verbal como objeto de análise. Entre eles podemos apontar: vídeos, documentários, filmes, entre outras possíveis materialidades não-verbais que produzem sentido e que, por conseguinte, estão sujeitas à interpretação, sendo, portanto, objetos tão legítimos de uma análise de discurso quanto uma materialidade verbal (INDURSKY, 2011, p. 200).

É tomando o discurso, então, como materialidade da ideologia e a língua como materialidade do discurso, que é possível pensar o discurso fílmico e o discurso literário. É a partir na noção de materialidade que se compreende ser possível desenvolver análise de discursos que incluam, além da língua, outras formas de materialização da ideologia.

Orlandi, retomando Pêcheux, observa que

é preciso levar a sério a noção de materialidade discursiva enquanto nível de existência sócio-histórica. E não é a língua, nem a literatura, nem as 'mentalidades' de uma época, pois a materialidade discursiva, diz Pêcheux, remete às condições verbais de existência dos objetos (científicos, estéticos, ideológicos) em uma conjuntura histórica dada (ORLANDI, 2012, p. 44).

Procurarei, então, apresentar uma análise da cena narrativo-fílmica e da cena narrativo-literária da leitura do depoimento de um preso político durante a ditadura militar brasileira, atentando para os aspectos linguísticos, mas também levando em consideração alguns elementos de imagem no intento de ver como se dá a constituição dos possíveis efeitos de sentido que são produzidos. O recorte do filme e o recorte do livro serão considerados como sequências discursivas a serem analisadas. 


\section{As meninas: o romance}

As meninas é um romance escrito por Lygia Fagundes Telles publicado em 197322. Ambientado na cidade de São Paulo, num pensionato religioso, narra um período da vida de três jovens com histórias bastante distintas. Tratam-se de Lorena, Lia e Ana Clara, as personagens principais, cujas vozes ressoam nos 12 capítulos. $\mathrm{O}$ período de desenvolvimento da história é o período de duração da greve da universidade que, no contexto do livro, ocorre em 1971, em plena ditadura militar brasileira.

As condições de produção do romance com forte crítica ao sistema político vigente são dos anos opressores da ditadura. A narrativa trata da história de três adolescentes que permanecem num internato enquanto as outras meninas aproveitam a greve da universidade para voltar para casa e ficar com a família. Assim, na chamada "pensão", ficam as três protagonistas acompanhadas das freiras que ali também habitam. Lorena representa a alta burguesia, a sonhadora de bom coração. Lia é a revolucionária marxista militante do movimento de resistência à ditadura. E Ana Clara, por vezes chamada de Ana Turva, teve uma infância marcada pelo abuso sexual e trabalha como modelo.

De acordo com Torquato, essas meninas "aparentemente protegidas pelo pensionato religioso no qual residem, atravessam juntas os conflitos da juventude urbana em plena ditadura militar" (2007, p.12). Entretanto, acrescenta a autora,

não se trata de um romance que aborda gratuitamente a ditadura, mas de um romance no qual a ditadura, enquanto drama sentido cotidianamente, faz-se refletir através do universo de três meninas tão diferentes nas origens, nos sonhos, na personalidade e na ideologia (TORQUATO, 2007, p. 12).

Apesar de conter uma crítica à ditadura, seja através das ações de Lia, seja através do depoimento do preso político descrito no capítulo seis, o romance passou pela censura institucional da arte.

22 O livro foi vencedor dos seguintes prêmios: Prêmio Coelho Neto, da Academia Brasileira de Letras (1974); Prêmio Jabuti, da Câmara Brasileira do Livro (1973) e Prêmio 'Ficção', da Associação Paulista de Críticos de Arte (1974). 
As meninas: uma análise dos efeitos de sentido produzidos a partir do funcionamento discursivo do depoimento de um preso político no discurso fílmico e literário | 65 Em entrevista para Sonia Racy, do jornal Estadão ${ }^{23}$, Lygia relata como o livro burlou a censura:

Sim, a censura! Publiquei As Meninas em plena ditadura militar, no ano de 1973. Oportuno lembrar que a personagem Lia, apelidada de Lião pelas outras meninas, foi a socialista que reproduziu fielmente um panfleto que recebi enquanto escrevia o livro. Nele, um preso político descrevia as torturas que sofreu nos porões do DOICODI, em São Paulo.

E como As Meninas escapou da censura?

Porque o censor da época não chegou até a página $148^{24}$ do livro, na qual reproduzi aquele panfleto. Ele achou tudo chato e não prosseguiu.

O que se disse faz pensar como o discurso da ditadura, minado de memórias sobre a censura e a dor, funcionando através da historicidade inscrita no interdiscurso, e pelas diferentes condições de produção em que emerge cada vez que se atualiza, em cada época, vai produzir sentidos.

A obra literária vem a constituir-se numa materialização de escape à prática da censura como um contradiscurso no seio de um sistema ditatorial e que funciona pela contradição da reprodução/transformação das relações de poder em disputa na dinâmica ideológica da luta classes na formação/estruturação das instituições. $O$ romance, portanto, como manifestação discursiva, irrompe por essa burla ao sistema opressorditatorial. $\mathrm{O}$ que coloca em evidência a capacidade de ignorância do próprio sistema ditatorial. Trata-se de uma percepção do literário como discurso, pois embreado numa rede histórica, variando conforme as ideologias e formações sociais, e concebido como aquilo que resiste à lei.

\footnotetext{
23 Disponível em http://www.estadao.com.br/noticias/geral,direto-dafonte, 485160 . Acesso em 16 de maio de 2018.

${ }^{24}$ A edição lida para este trabalho é a $15^{a}$, portanto a página em que aparece o depoimento é a 135 .
} 
Torquato considera que As Meninas pode ser caracterizado como romance polifônico e dialógico. A autora propõe que a polifonia se mostra na combinação de

três vozes plenivalentes e imiscíveis mas em constante interação, uma vez que as consciências das protagonistas travam relações dialógicas a todo instante, interpondo-se e contrapondo-se tanto nos diálogos quanto nos monólogos interiores. (...) além das três narradoras, há um narrador "ausente" da matéria narrada que intercala as diferentes falas. Podemos dizer, portanto, que há uma voz externa e três vozes internas (TORQUATO, 2007, p. 13).

Nesse entremeio de narradores, outros discursos se fazem presentes, e constituem lugares de atravessamento, oriundos da religião e da ditadura, como veremos a partir da análise das cenas em que é feita a leitura do depoimento do torturado.

No livro, antes de chegar à cena, é preciso relatar o que lhe precede. Trata-se do capítulo seis, a metade da obra, o exato meio termo. A narradora é Lia. Ela chega à pensão depois de ter ido visitar um companheiro de luta num esconderijo. Lá, tratam-se pelos codinomes: Lia é Rosa, o outro é Pedro, de quem não se vem a saber o verdadeiro nome ${ }^{25}$. Lia está de carona no carro com Bugre. $\mathrm{O}$ diálogo entre os dois sugere que este sujeito-personagem tem um posto significativo no movimento para deter informações privilegiadas, pois é ele que lhe dá a notícia de que Miguel, o namorado de Lia, está na lista dos presos políticos a serem asilados na Argélia. Lia chega para o encontro com Madre Alix embebida com a possibilidade de se reencontrar com seu namorado Miguel, ainda que em outro país. É quando ela relata sobre o depoimento do preso torturado.

\footnotetext{
${ }^{25}$ Aqui também aparecem nomes importantes, defensores do marxismo e da luta armada, como Rosa de Luxemburgo e Che Guevara. "Rosa de Luxemburgo era bonita?", pergunta Pedro na despedida. (TELLES, 1984, p. 119).
} 
As meninas: uma análise dos efeitos de sentido produzidos a partir do funcionamento discursivo do depoimento de um preso político no discurso fílmico e literário | 67

As meninas: o filme

O filme As meninas ${ }^{26}$ surge no cenário cinematográfico em 1996, em outras condições de produção culturais e políticas brasileiras. A Constituição Federal, que marca o início legal da frágil democracia no país, tem oito anos. A prática seletiva do olhar do censor não era mais uma sombra a fazer efeito no trabalho do artista. Os empecilhos eram de outra ordem para a produção cinematográfica brasileira. O importante é que cerca de 10 anos depois, a memória da ditadura retorna na obra fílmica.

Veloso apresenta a expressão "discurso narrativo fílmico" para caracterizar o discurso que é constitutivamente

sustentado por uma combinação de imagens que, estáticas ou em movimento, servem de ambientação a personagens-sujeitos discursivos em situações simuladoras de condições de produção discursiva reais (VELOSO, 2010, p.20).

Levando isso em consideração, é preciso remeter às condições de produção das obras como acontecimentos na história e às cenas narrativodiscursivas onde interagem os sujeitos-personagens. Destaco, para a análise, três possibilidades de constituição do momento de produção do discurso enquanto resistência, ainda que solapado pelas engrenagens da ideologia: [1] o lançamento e a premiação de um romance escrito que critica o sistema político-ditatorial vigente à época, constituindo-se também como discurso literário que critica a ordem da censura e a burla; [2] os sujeitos-personagens na cena narrativa-literária, que faz referência a um fato histórico "real", que se desenrolava no "tempo presente da ditadura" e; [3] os sujeitos-personagens na cena narrativa-fílmica, em certo momento estético e ideológico do cinema brasileiro, já inserido numa conjuntura política democrática. A análise que segue busca observar

26 filme também é vencedor de vários prêmios: Prêmio Catalina de Oro, Festival Internacional de Cine de Cartagena (1996) nas categorias Melhor Roteiro e Melhor Atriz para Adriana Esteves pela sua interpretação como Lorena; Prêmio da Crítica, International Critics Award - Fédération Internacionale de la Presse Cinématographique; Prêmio no XVII Festival Internancional del Nuevo Cine Latino Americano, Havana/Cuba, na categoria melhor atriz para Cláudia Liz pela interpretação de Ana Clara. 
como esses três diferentes momentos de produção do discurso estão entrelaçados na produção de sentidos.

As meninas: análise em bordado de duas linhas discursivas

Voltemos à cena narrativa-literária e ao início do diálogo entre Lia e Madre Alix. Lemos:

- Que tempo - resmungou se sacudindo no vestíbulo do casarão.

- Lia? É você, Lia? - perguntou Madre Alix abrindo a porta do seu gabinete. Entre um instante, filha. Sente-se. Aqui ao meu lado. Quer tomar um café? Foi feito há pouco, vê se está bom de açúcar.

Lia deixou a sacola e o livro no chão. Sorriu desamparada. Queria ficar só, pensando e repensando.

- Insônia, Madre Alix? (TELLES, 1984, p. 129)

Por esse recorte, podemos perceber que o espaço onde ocorre a cena é dentro da pensão, mais precisamente no gabinete da Madre Superiora, e à noite. A presença do café, bom de açúcar, parece aromatizar o casarão. $\mathrm{O}$ tratamento por filha demonstra a intimidade que há entre as duas, ainda que a cada the pertençam seus segredos. No diálogo que segue, Lia se pronuncia em primeira pessoa. Fico olhando o relógio em formato de oito, dependurado na parede caiada de branco. O som também é antigo (idem, p. 129). A Madre quer falar em vestidos, e ela pensa na Argélia. Parece uma estratégia maternal, para tocar assuntos mais profundos. A Madre se preocupa com a vida que levam as meninas. Expõe sua preocupação com as atitudes de Ana Clara na sua relação com as drogas e os namorados. Ela parece entender o tormento e querer ajudar. Lia pensa no seu presente. Vê Ana Clara como produto desta nossa sociedade (idem, p. 132). A Madre, então, revela o assunto que the impulsionou o convite ao café. Diz ela:

- Tinha tanta coisa que lhe dizer, filha. E já nem sei por onde começar. Essa sua política, por exemplo. Me pergunto se você está em segurança. 
As meninas: uma análise dos efeitos de sentido produzidos a partir do funcionamento discursivo do depoimento de um preso político no discurso fílmico e literário | 69

- Segurança? Mas quem é que está em segurança? Aparentemente a senhora pode parecer muito segura aí na sua redoma mas é bastante inteligente pra perceber do que essa redoma está the protegendo. (...)

Ela sorriu. Um sorriso triste que me arrependi de provocar.

- Mas não estou na redoma, Lia. (...) (TELLES, 1984, p. 133)

A maneira como essa passagem do livro é transposta para o discurso fílmico revela diferenças, como era de se esperar, pois se tratam de linguagens diferentes, a literatura e o cinema, embora, tenham intrincadas relações. Diferente do livro, no filme, Lia chega à pensão depois de ter ido visitar seu namorado Miguel. Ele lhe entrega uma folha de caderno com o depoimento escrito das torturas de outro preso. Neste momento do filme, Lia ainda não sabe se Miguel vai entrar para a lista dos anistiados na Argélia. Ela não volta no carro de Bugre. Ao chegar no casarão, vai ao quarto de Lorena onde toma um banho de banheira, e não ao gabinete. No livro, a cena se desenrola durante a noite, ao aroma de café. No filme, é durante o dia e fora da casa.

No filme, o início da cena do diálogo entre Lia e Madre Alix se dá ainda quando Lia mergulha na banheira. A cena fecha em seu rosto imergindo na banheira azul. Entra uma trilha sonora suave. Irrompe sua própria fala, como narradora onipresente, iniciada no close $^{27}$ final desta cena e terminada no início da cena, em plano aberto ${ }^{28}$, em que ela e Madre Alix estão sentadas próximo a um muro de pedras. No instante do mergulho, ouvimos Lia dizer: As pessoas acham que minha crença na justiça é uma questão religiosa. O término do enunciado se dá com a câmera focando as duas personagens-fílmicas sentadas num banco próximo ao muro. A Lorena fica falando que eu sou crente [28'28" - 28'31"] ${ }^{29}$. Ao que pergunta a Madre: Você acredita em quê? Eu acredito na gente, sabe? [28'33 28'35”], responde Lia. Semelhante ao livro, elas falam da família de Lia,

\footnotetext{
${ }^{27}$ Plano muito próximo que mostra, por exemplo, somente a cabeça de um ator, dominando praticamente toda a tela (ANCINE, 2008).

${ }^{28}$ Plano que inclui todo o cenário (ANCINE, 2008).

29 Indica a duração das sequências fílmicas, levando em conta o contador do programa de vídeo.
} 
mas no filme não tratam de Ana Clara. No mesmo tom maternal de tratamento por minha filha, a Madre revela o motivo da conversa.

[Madre] Essa sua luta política. Eu tenho medo pela sua segurança.

[Lia] Segurança, Madre! Quem é que tá em segurança? Aparentemente, a senhora se sente muito segura nessa sua redoma, mas é bastante bem informada pra saber do que essa redoma tá te protegendo. Esse país tá um caos e a senhora vem falar em segurança.

[Madre] Eu ... eu não estou em redoma, minha filha. [ 29'20”- 29'47”]

Madre Alix irrompe com um discurso religioso e a defesa de que, para o Ser Supremo, não há violência. No livro, a Madre diz: Temos um Condutor Supremo e do Seu esquema transcendente a violência foi riscada (TELLES, 1984, p. 134). No filme: Eu sinto dentro de mim um condutor supremo e no seu universo não há violência [29'54" -30'03"].

Lia se contrapõe e irrompe propondo a leitura do depoimento do preso torturado, como materialização da violência opressora e injusta. Assim, no livro ela diz: Quero que ouça o trecho de um depoimento de um botânico perante a Justiça, ele ousou distribuir panfletos numa fábrica. Foi preso e levado à caserna policial, ouça aqui o que ele diz, não vou ler tudo: (...) (TELLES, 1984, p. 135).

No filme, Lia faz a entrada para a leitura do depoimento usando outros termos. Diz ela: Agora já que a senhora falou em violência, vou the mostrar uma [30'37" - 30'38"]. Sentada ao lado da Madre, ela retira a folha de caderno do bolso esquerdo da camisa de algodão azul, desdobra e começa a ler em voz alta, enquanto suas mãos tremem incondicionalmente. Lia, no filme, não começa pelo início e nem lê todas as partes que constam no livro ${ }^{30}$. Como forma de recorte, procurou-se destacar apenas os trechos que são coincidentes nas duas obras.

No livro, o depoimento é lido em voz alta por Lia. O leitor, naquele instante, pode dar o tom de $v^{31}$ que quiser ao escritor do

\footnotetext{
$30 \mathrm{O}$ depoimento do livro é um trecho de um texto mais longo publicado num panfleto verdadeiro distribuído durante o período de ditadura militar no Brasil.

${ }^{31}$ Nesse sentido, literalmente a produção de sons, e não o construto teórico proposto pela Enunciação.
} 
As meninas: uma análise dos efeitos de sentido produzidos a partir do funcionamento discursivo do depoimento de um preso político no discurso fílmico e literário | 71 depoimento, no filme, se "escutam" as vozes das atrizes-sujeitospersonagem Lia/DricaMoraes e Madre Alix/Camilla Amado. A voz tremida, permeada pelo soluço do choro, quando Lia fala, e baixa e cadenciada, quando a Madre fala.

Primeiro me perguntaram se eu pertencia a um grupo político. Neguei. Enrolaram então alguns fios em redor dos meus dedos, iniciando-se a tortura elétrica: (...) Obrigaram-me então a aplicar choques em mim mesmo e em meus amigos. Para que eu não gritasse enfiaram um sapato dentro da minha boca. Outras vezes panos fétidos. Após algumas horas, a cerimônia atingiu seu ápice. [30'49” - 31'25”]

A tremura de suas mãos é tão intensa que resulta na impossibilidade de continuar. Ela cai em prantos, tomada pela catarse. Madre Alix toma a folha de caderno de suas mãos e segue a leitura em voz alta.

Penduraram-me no pau-de-arara: amarraram minhas mãos diante dos joelhos, atrás dos quais enfiaram uma vara, cujas pontas eram colocadas em mesas. Fiquei pairando no ar. [31'31" 31'55"]

Durante a leitura feita pela Madre, a voz de uma soprano irrompe como trilha sonora através de uma melodia suave. Confunde-se com o choro de Lia e a voz da Madre. O que se "ouve" é o silêncio do som da voz do preso. O silêncio, entendido aqui na acepção de Orlandi (1993), como significante na estrutura da língua, potencialidade de sentido. A voz do preso surge, no filme, "na" voz das atrizes/personagens; através da leitura, a voz do preso ressoa no imaginário do leitor do romance. $\mathrm{O}$ som da denúncia do depoimento não existe senão através do silêncio como fundante do discurso. É na "não-voz" do torturado que o silêncio funciona, trabalhando, na própria contradição, a crítica ao processo de silenciamento imposto por um regime político que inflige a tortura do ao pensar diferente da ordem do sistema. 
A opção do diretor em não colocar "um som da voz original" do autor do depoimento, como um recurso de locução em off é indicativo da presença deste silêncio. A locução em off é uma estratégia cinematográfica: é o texto que acompanha a ação do filme, pronunciado por um locutor que não aparece na cena, quando da leitura de uma carta, por exemplo. Geralmente, vemos o personagem ou a carta em primeiro plano e em locução em off a voz do autor da carta. No presente caso, a leitura do depoimento foi feito pelas personagens-fílmicas, não havendo o recurso de trazer uma voz "estranha" para representar o dito no depoimento. A voz das personagens apaga o silêncio da voz do preso.

Surpreendendo Lia, a Madre revela: Eu conheço bem isso, minha filha. O rapaz se chama Bernardo. Tenho estado sempre muito com a mãe dele. Fomos juntas pedir a intervenção do Cardeal. [31'59" - 33'12"]. Lia, quase de costas para a Madre, agora sem chorar, olha longe o horizonte. A Madre olha para ela. Lia se volta, as duas se olham nos olhos, a Madre acena afirmativamente com a cabeça, num movimento de confirmação de que também está na luta através de outros caminhos.

Voltemos ao livro. A sequência final do diálogo assim se dá:

Dobro a folha. Madre Alix me encara. Os olhos cinzentos têm uma expressão afável.

- Conheço isso, filha. Esse moço chama-se Bernardo. Tenho estado muito com a mãe dele, fomos juntas falar com o Cardeal.

(...)

Ela me acompanha até a porta.

- Posso the dar uma epigrafe? É do Gênesis, aceita? - pergunta e sorri: Sai da tua terra e da tua parentela e da casa de teu pai e vem para a terra que eu te mostrarei. É o que você está fazendo - acrescentou. Hesitou um pouco: - É o que en fiz. (TELLES, 1984, p. 136)

Encerra-se a cena fílmica, encerra-se a cena literária. Porém, a ditadura parece perdurar. Nos três momentos de produção do discurso de resistência à ditadura, é possível ver o trabalho do silêncio fazendo funcionar a crítica e a denúncia. Ele está marcado no silêncio no censor, em não listar como proibido aquilo que, consoante o sistema, deveria ser: o lançamento de um romance onde se lê o depoimento de um preso dizer 
As meninas: uma análise dos efeitos de sentido produzidos a partir do funcionamento discursivo do depoimento de um preso político no discurso fílmico e literário | 73

que foi torturado. No livro, o silêncio ressoa através de Lia, mas pode o leitor ainda preferir ouvir a voz do depoente. O imaginário pode destacar outros sentidos para o silêncio neste caso. O silêncio no filme está presente nos tons de Drica/Lia e Madre/Camilla, também marcado no discurso direto, mas funcionando diferentemente, possibilitando a produção de outros sentidos.

\section{REFERÊNCIAS}

ANCINE. GLOSSÁRIO DE TERMOS TÉCNICOS DO CINEMA E DO AUDIOVISUAL. [S.I.]: ANCINE, 2008. p. 1-68.

AS MENINAS. Direção de Emiliano Ribeiro. Produção de Carlos Moletta. Produção Executiva de Emiliano Ribeiro, Lygia Fagundes Telles e Sam Ansell. Roteiro Adaptado: Onézio Paiva e David Neves. Música: Carlos Moletta. 1995. (90 min.), 35 mm, son., color.

INDURSKY, Freda. A luta pela terra: borrando limites entre o rural e o urbano. In: RODRIGUES, Eduardo Alves; SANTOS, Gabriel Leopoldino dos; BRANCO, Luiza Katia Andrade Castello (Org.). Análise de Discurso no Brasil: Pensando o Impensado Sempre Uma homenagem a Eni Orlandi. Campinas: Editora RG, 2011. p. 197220.

ORLANDI, Eni Puccinelli. As formas do silêncio: no movimento dos sentidos. 2. ed. Campinas: Editora da Unicamp, 1993.

. Discurso em análise: sujeito, sentido e ideologia. Campinas: Pontes, 2012.

TELLES, Lygya Fagundes. As meninas. 15. ed. Rio de Janeiro: Nova Fronteira, 1984.

TORQUATO, Carolina P. Aspectos da polifonia no romance As Meninas, de Lygia Fagundes Telles, e sua tradução para o italiano. In: Terra Roxa e Outras Terras: Revista de Estudos Literários, Londrina, v. 11, n. 1-131, p. 12-19, 2007.

VELOSO, Maria Thereza. Entre a privação e o silenciamento:o sujeito do desejo na trama discursiva de Todo sobre mi madre. 2010. $184 \mathrm{f}$. Tese (Doutorado) - Curso de Doutorado em Letras, PPGL, UCPel, Pelotas, 2010. 
74 | Cristina Zanella Rodrigues

Recebido em: 02/06/2018

Aceito em: 09/07/18

Caderno de Letras, no 32, Set-Dez - 2018 - ISSN 0102-9576 